\title{
Application limits of Q-switched Nd:YAG laser irradiation for stone cleaning based on colour measurements
}

\author{
R.M. Esbert ${ }^{\text {a }}$, C.M. Grossi ${ }^{\text {a, } *}$, A. Rojo ${ }^{\text {a }}$, F.J. Alonso ${ }^{\text {a }}$, M. Montoto ${ }^{\text {a }}$, J. Ordaz ${ }^{\text {a }}$, \\ M.C. Pérez de Andrés ${ }^{b}$, C. Escudero ${ }^{b}$, M. Barrera ${ }^{b}$, E. Sebastián ${ }^{c}$, C. Rodríguez-Navarro ${ }^{c}$, \\ K. Elert ${ }^{\mathrm{c}}$
}

\begin{abstract}
The application limits of the laser-cleaning technique for different types of building stones have been investigated by measuring colour variations. The selected stones differ in their chemical and mineralogical composition, colour, texture and crystallinity degree. The experimentation was carried out with a Q-switched Nd:YAG laser. The colour variations on stones associated with different operative fluences were measured using a colorimeter. Further, surface morphological changes were examined under SEM. From the calculation of colour differences, a damage threshold fluence was established for each stone type. The response of the stones to laser radiation at a particular fluence was found to be mainly conditioned by their chemical and mineralogical composition and, to a less extent, by their textural characteristics. (c) 2003 Éditions scientifiques et médicales Elsevier SAS. All rights reserved.
\end{abstract}

Keywords: Stone conservation; Laser cleaning; Limestone; Marble; Granite; Damage thresholds

\section{Research aims}

Colour is an essential and highly laser-vulnerable characteristic in stone conservation. Therefore, the aim of this research is to investigate the application limits of the laser-cleaning technique for different types of monumental and ornamental stones on the basis of the measured colour variations.

\section{Introduction}

The conditions of application of the laser technique and the optimum laser parameters have been widely studied [1-4]. When using laser radiation for the cleaning of monumental stones, it is extremely important to determine the threshold fluence that could damage the stone surface. This laser fluence damage threshold in cleaning processes strongly depends on the main laser parameters (pulse energy, pulse duration and pulse frequency rate), the irra-

\footnotetext{
* Corresponding author.

E-mail address: mgrossi@asturias.geol.uniovi.es (C.M. Grossi).
}

diation conditions and the substratum characteristics (e.g., texture and composition).

As stated before, stone colour is an essential and highly laser-vulnerable characteristic in stone conservation. The dominant hue is to some extent related to the content, state of oxidation and type of compound of iron $(\mathrm{Fe})$. $\mathrm{Fe}$ is a very absorbing and sensitive element to $1064 \mathrm{~nm}$ laser radiation and colour changes are usually attributed to changes in the different oxidation states of Fe-rich compounds [3-6].

In this paper, the damage threshold fluence for several building stones is estimated from the calculation of colour differences. As most of the authors found that the use of a thin water layer enhances the laser-cleaning efficiency [2-4], dry and wet stone surfaces were irradiated and colour changes compared.

\section{Materials}

Three different limestones (Hontoria, Santa Pudia and Piedramuelle), a marble (Macael) and a granite (Rosa Porriño) were selected. The limestones have been used in the cathedrals of Burgos, Granada and Oviedo, respectively, 
Table 1

Petrographic characteristics of the selected stones

\begin{tabular}{|c|c|c|c|c|c|c|c|}
\hline Stone & Source & Rock type & Texture & Grain size (mm) & Main colour (hue) & Porosity (\%) & $\mathrm{Fe}_{2} \mathrm{O}_{3}(\%)$ \\
\hline Hontoria & Burgos & Limestone & Bioclastic & 2 & White & 25 & 0.01 \\
\hline Santa Pudia & Granada & Limestone & Bioclastic & 0.6 & Buff & 30 & 0.42 \\
\hline Piedramuelle & Oviedo & Limestone & Crystalline & 0.2 & Red & 10 & 4.25 \\
\hline Macael & Almería & Marble & Crystalline & 0.8 & White & 0.5 & $0.06-0.37$ \\
\hline Porriño & Pontevedra & Granite & Crystalline & 20 & Pink & 1.5 & 2.97 \\
\hline
\end{tabular}

Table 2

Original colour parameters

\begin{tabular}{llrrrrr}
\hline Stone & & \multicolumn{1}{c}{$L^{*}$} & \multicolumn{1}{c}{$a^{*}$} & \multicolumn{1}{c}{$b^{*}$} & \multicolumn{1}{c}{$C^{*}$} & \multicolumn{1}{c}{$h$} \\
\hline Hontoria & Mean & 89.9 & 1.5 & 7.3 & 7.4 & 78.1 \\
\multirow{2}{*}{ Santa Pudia } & Std & 0.9 & 0.3 & 1.0 & 1.0 & 2.0 \\
& Mean & 84.4 & 0.7 & 12.6 & 12.6 & 87.0 \\
Piedramuelle & Std & 0.5 & 0.1 & 0.9 & 0.9 & 0.4 \\
& Mean & 59.1 & 11.9 & 21.5 & 24.6 & 60.9 \\
Macael & Std & 1.5 & 0.9 & 2.1 & 2.2 & 1.7 \\
& Mean & 77.0 & -1.1 & -1.0 & 1.6 & 220.0 \\
Porriño & Std & 3.0 & 0.2 & 0.6 & 0.3 & 19.0 \\
& Mean & 61.5 & 2.9 & 7.2 & 7.8 & 71.3 \\
& Std & 4.9 & 2.0 & 2.6 & 3.1 & 10.2 \\
\hline
\end{tabular}

$L^{*}=$ lightness $(0$ : black to 100 : white $) ; a^{*}=$ red-green axis $(+:$ red; - : green); $b^{*}=$ yellow-blue axis $(+:$ yellow; - : blue $) ; C^{*}=$ chroma $\left[\left(a^{* 2}+b^{* 2}\right)^{1 / 2}\right] ; h=$ hue $\left[\arctan \left(b^{*} / a^{*}\right)\right]$. Number of measurements: $45-50$.

and the marble in the Alhambra of Granada. The Rosa Porriño granite is one of the most marketed ornamental stones in Spain. All the specimens are quarry materials. Surface finishes were polished for Rosa Porriño and sawn for the rest of the stones, which exhibited the following increasing surface roughness sequence: Macael, Piedramuelle, Hontoria and Santa Pudia. Table 1 summarises the most relevant petrographic characteristics of these stones.

\section{Experimental methodology}

Experiments were carried out on the selected stones using a Q-switching Nd:YAG laser system; $\lambda=1064$ nm; spot diameter $=6 \mathrm{~mm}$; pulse frequency rate $=20 \mathrm{~Hz}$; pulse duration $=6 \mathrm{~ns}$ and maximum pulse energy varying around
353-415 mJ. Two different irradiation procedures were employed:

(A) Laser irradiation was performed on dry stone tablet specimens (surface: $50 \mathrm{~mm} \times 50 \mathrm{~mm}$ ) along different strips. Each strip was irradiated at a different fluence: $0.37,0.50$, $0.75,1.0$ and $1.25 \mathrm{~J} \mathrm{~cm}^{-2}$. Strips were irradiated five times using an articulated arm manually handed by the restorer along the strip. A total time of around 10 min was necessary to irradiate each strip. Some stone surfaces showed damage even at the lowest fluence $\left(0.37 \mathrm{~J} \mathrm{~cm}^{-2}\right)$. Therefore, a second set of strips was irradiated with laser at other fluences, which were selected according to the results of the first set.

(B) Laser radiation was applied to dry and wet surfaces (applying a thin layer of water before laser irradiation) of stone tablets (tested surface: $50 \mathrm{~mm} \times 50 \mathrm{~mm}$ ) at two different fluences $\left(0.5\right.$ and $\left.1.47 \mathrm{~J} \mathrm{~cm}^{-2}\right)$.

In both experiments ( $\mathrm{A}$ and $\mathrm{B}$ ), irradiated area length, surface, energy and time of application were recorded to evaluate fluence, number of pulses and applied power. Prior to and after each experiment, colour was measured using a colorimeter Minolta CR-200, equipped with a xenon lamp that produces a beam of diffuse light of $8 \mathrm{~mm}$ of diameter. The colour-systems used were CIE $L^{*} a^{*} b^{*}$ and CIE $L^{*} C^{*} h$. Total colour difference was calculated as follows: $\Delta E^{*}=\left(\Delta L^{* 2}+\Delta a^{* 2}+\Delta b^{* 2}\right)^{1 / 2}$. Data were statistically treated in order to detect significant differences.

Furthermore, small stone specimens (surface: $20 \mathrm{~mm}$ $\times 20 \mathrm{~mm}$ ) were irradiated at different fluences and number of pulses; later they were examined under scanning electron microscopy (SEM) for detecting morphological changes.

Table 3

Colour changes $\left(\Delta E^{*}\right)$ and Grey Scale values (GSc) (EN ISO 105-A05 [7]) at increasing fluences

\begin{tabular}{|c|c|c|c|c|c|c|c|c|c|c|}
\hline \multirow[t]{2}{*}{ Fluence $\mathrm{J} \mathrm{cm}^{-2}$} & \multicolumn{2}{|c|}{ Hontoria } & \multicolumn{2}{|c|}{ Santa Pudia } & \multicolumn{2}{|c|}{ Piedramuelle } & \multicolumn{2}{|c|}{ Macael } & \multicolumn{2}{|c|}{ Rosa Porriño } \\
\hline & $\Delta E^{*}$ & GSc & $\Delta E^{*}$ & GSc & $\Delta E^{*}$ & $\mathrm{GSc}$ & $\Delta \mathrm{E}^{*}$ & GSc & $\Delta \mathrm{E}^{*}$ & GSc \\
\hline 0.12 & - & - & - & - & 0.8 & 4.5 & 0.4 & 4.5 & 0.1 & 5 \\
\hline 0.15 & - & - & - & - & 0.5 & 4.5 & - & - & 0.6 & 4.5 \\
\hline 0.19 & - & - & - & - & 0.7 & 4.5 & 0.3 & 5 & - & - \\
\hline 0.22 & - & - & - & - & 1.0 & 4.5 & - & - & - & - \\
\hline 0.25 & 0.5 & 4.5 & 1.1 & 4.5 & 0.8 & 4.5 & 0.5 & 4.5 & 1.1 & 4 \\
\hline 0.31 & 0.5 & 4.5 & 0.6 & 4.5 & 2.3 & 3.5 & 0.4 & 4.5 & - & - \\
\hline 0.37 & 0.6 & 4.5 & 0.8 & 4.5 & 3.0 & 3 & 0.4 & 4.5 & 0.5 & 4.5 \\
\hline 0.50 & 0.4 & 5 & 1.2 & 4.5 & 7.2 & 2 & 2.5 & 3.5 & 1.8 & 4 \\
\hline 0.75 & 1.0 & 4.5 & 1.9 & 4 & 11.9 & 1 & 4.0 & 3 & 2.1 & 3.5 \\
\hline 1.00 & 1.4 & 4 & 1.4 & 4 & 13.3 & 1 & 5.0 & 2.5 & - & - \\
\hline 1.25 & 1.5 & 4 & 1.5 & 4 & 12.1 & 1 & 5.7 & 2.5 & 2.5 & 3.5 \\
\hline
\end{tabular}



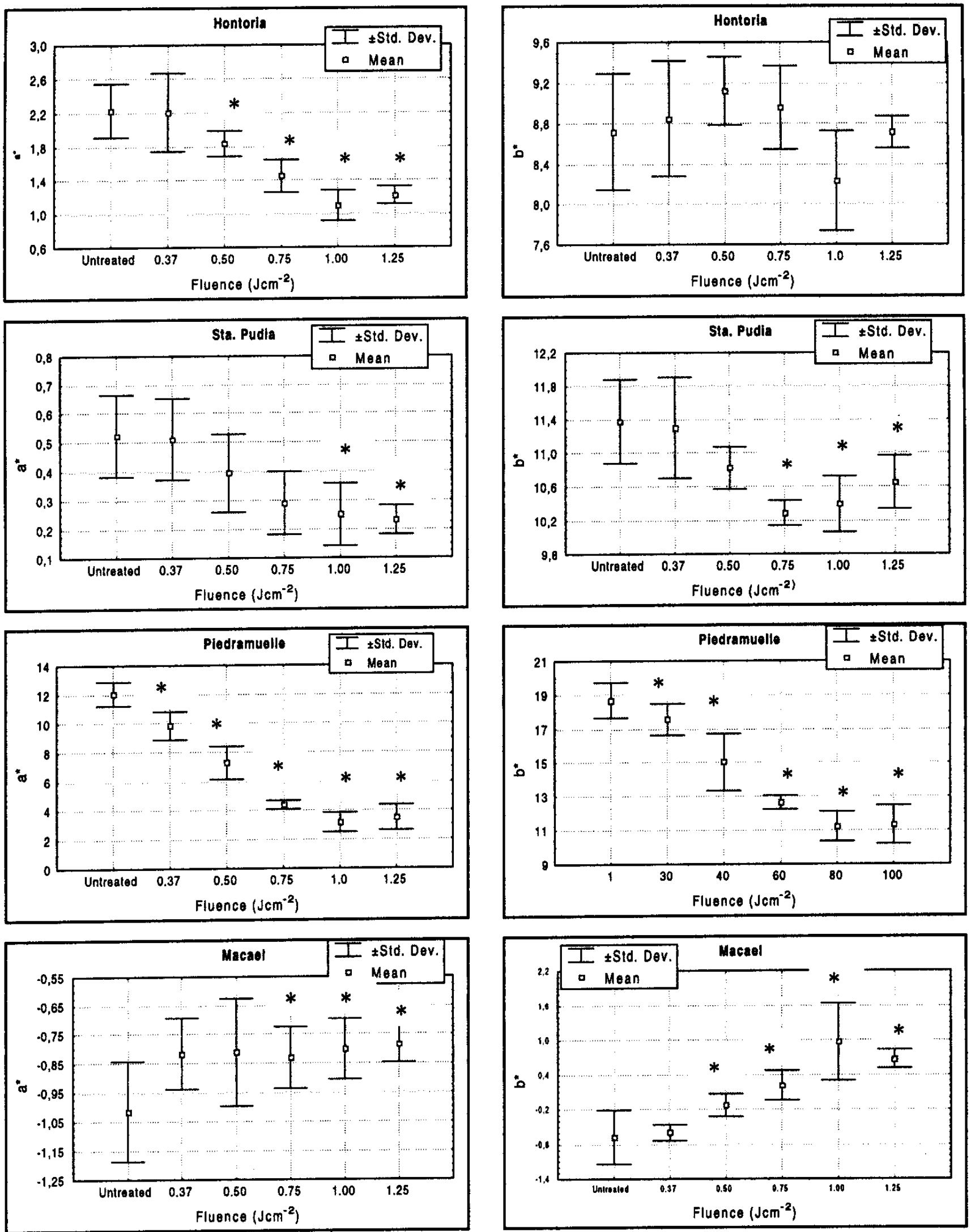

Fig. 1. Changes in $a^{*}$ and $b^{*}$ with increasing fluence. Carbonate stones. $*=$ significant at $P \leq 0.05$. 


\section{Results and discussion}

The selected stones have different colour characteristics, which are summarised in Table 2. Lightness varies from 90 (white Hontoria) to 59 (dark Piedramuelle) and chroma from 25 (intensely coloured Piedramuelle) to 2 (white marble). Hue is yellow dominant in the limestones, varying from 87 (yellowish Santa Pudia) to 60 (red Piedramuelle) and green-blue dominant $(h \approx 220)$ in the marble. The average colour of Rosa Porriño results from a combination of the granite rock-forming minerals (i.e., black biotite, pinkish feldspar and colourless quartz). These different coloured stones show different responses to laser irradiation.

On the whole, colour changes are higher at higher laser fluences. Total colour variations $\left(\Delta E^{*}\right)$ with increasing fluences are shown in Table 3. The table also shows Grey Scale values (GSc), which indicate approximately human sensibility to colour variation [7]. Values of GSc near 5 and 4.5 mean no or limit human visual discrimination whereas values near 1 denote extreme colour changes.

In the reddish selected stones, the $a^{*}$ co-ordinate (redgreen) is very sensitive to laser radiation. Piedramuelle limestone (red and considerably Fe-rich) and Rosa Porriño granite (pinkish) exhibit an evident $a^{*}$ decrease with increasing laser fluence. Also white, very low Fe-content Hontoria limestone shows a significant $a^{*}$ decrease (Fig. 1), although not a visible colour change (Table 3 ). Specifically:

- Hontoria limestone exhibits a negligible effect. No evident visual colour change was appreciated at the maximum applied fluence. This stone shows a statistically significant decrease of $a^{*}$ from $0.50 \mathrm{~J} \mathrm{~cm}^{-2}$ onwards (Fig. 1).

- Santa Pudia limestone suffers a slight visual darkening. Decrease in $L^{*}$ is statistically significant from $0.50 \mathrm{~J} \mathrm{~cm}^{-2}$ onwards. At higher fluences, changes in $a^{*}$ and $b^{*}$ are also significant (Fig. 1).

- Piedramuelle limestone is strongly affected by laser radiation. The stone shows a very intense darkening and becomes greenish. Visual and significant changes in $L^{*}, a^{*}$ and $b^{*}$ were detected from a fluence of $0.31 \mathrm{~J} \mathrm{~cm}^{-2}$ (Fig. 1). However, possible changes mainly in $a^{*}$ and perhaps $b^{*}$ could occur at lower fluences.

- Macael marble shows an evident visual darkening from a fluence of $0.50 \mathrm{~J} \mathrm{~cm}^{-2}$. Darkening becomes very evident at a fluence of $1 \mathrm{~J} \mathrm{~cm}^{-2}$. Darkening is more intense on the greenish bearing muscovite and pyrite minerals bands than in the white non-banded areas of the marble.

- Rosa Porriño granite shows a visual colour change mainly associated to the pinkish potassium feldspar crystals that become whiter, exhibiting strong significant changes in $a^{*}$ from a fluence of $0.5 \mathrm{~J} \mathrm{~cm}^{-2}$ onwards. Also biotite exhibits a colour change to lighter tones. SEM observations revealed that biotite is the most affected mineral and can reach melting.
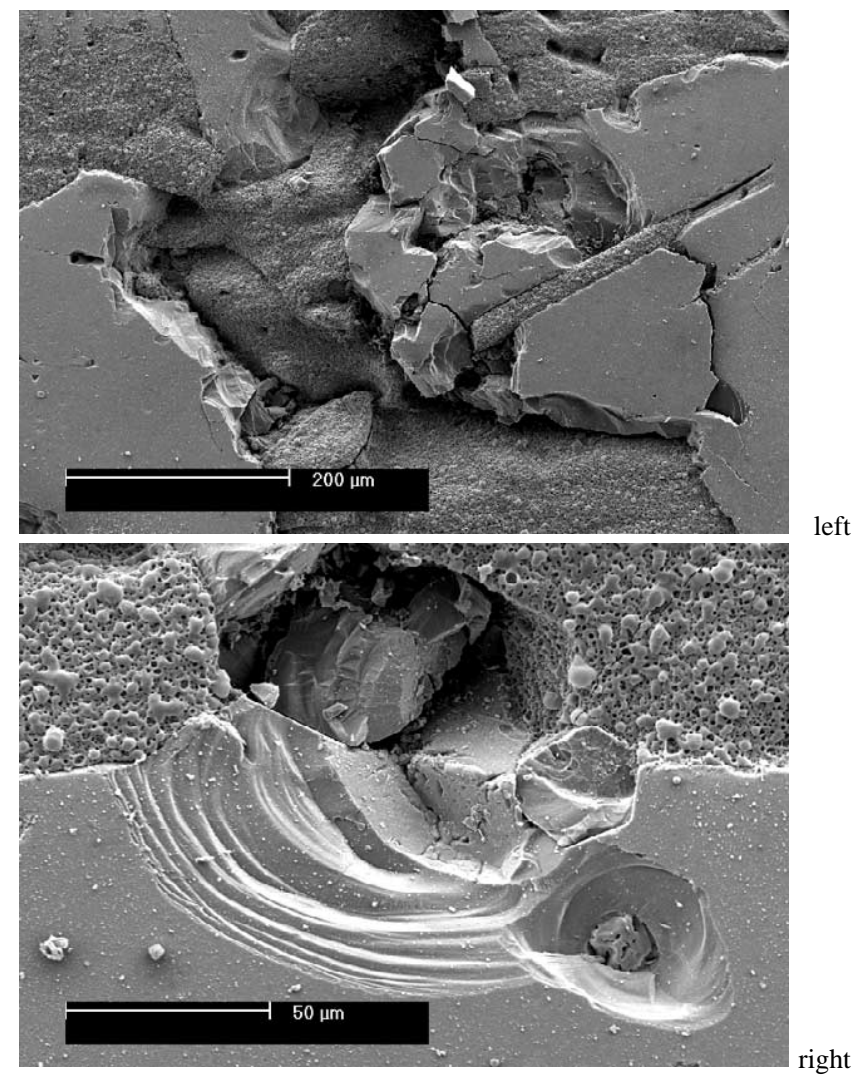

Fig. 2. SEM image of granite irradiated at $1.25 \mathrm{~J} \mathrm{~cm}^{-2}$ and 10 pulses. Left: biotite melting. Right: cleavage stepped fracture in quartz.

Quartz shows thermally induced brittle fracture, with cleavage stepped fracture (Fig. 2).

Surface wetting also influences stone response to laser radiation (Tables 4 and 5). Colour change is always higher on dry surfaces and is usually related to strong decreases in the $a^{*}$ co-ordinate. Colour change in Piedramuelle and Santa Pudia limestones also responds to $b^{*}$ decreases and in the case of Macael marble seems to be mainly related to $b^{*}$ variations.

Colour change on wet surfaces is generally below the human visual detection threshold. Only Piedramuelle limestone shows GSc values at $1.47 \mathrm{~J} \mathrm{~cm}^{-2}$ that evidence visual colour variations. Material ejection is also produced on wet surfaces of Piedramuelle limestone. Wet surfaces of limestones could also suffer a small but significant increase in the $b^{*}$ co-ordinate resulting in a subsequent chroma in-

Table 4

Colour changes ( $\left.\Delta E^{*}\right)$ and Grey Scale values (GSc) (EN ISO 105-A05 [7]) depending on surface conditioning $\left(1.47 \mathrm{~J} \mathrm{~cm}^{-2}\right.$ fluence $)$

\begin{tabular}{lrlll}
\hline Name & \multicolumn{2}{c}{ Dry } & \multicolumn{2}{l}{ Wet } \\
\cline { 2 - 5 } & \multicolumn{1}{c}{$\Delta E^{*}$} & GSc & $\Delta E^{*}$ & GSc \\
\hline Hontoria & 1.06 & 4.5 & 0.84 & 4.5 \\
Santa Pudia & 1.67 & 4 & 0.94 & 4.5 \\
Piedramuelle & 11.15 & 1.5 & 2.60 & 3.5 \\
Macael & 2.25 & 3.5 & 0.66 & 4.5 \\
Rosa Porriño & 2.47 & 3.5 & 2.01 & 4 \\
\hline
\end{tabular}

Results correspond to pulse cumulative effects. 


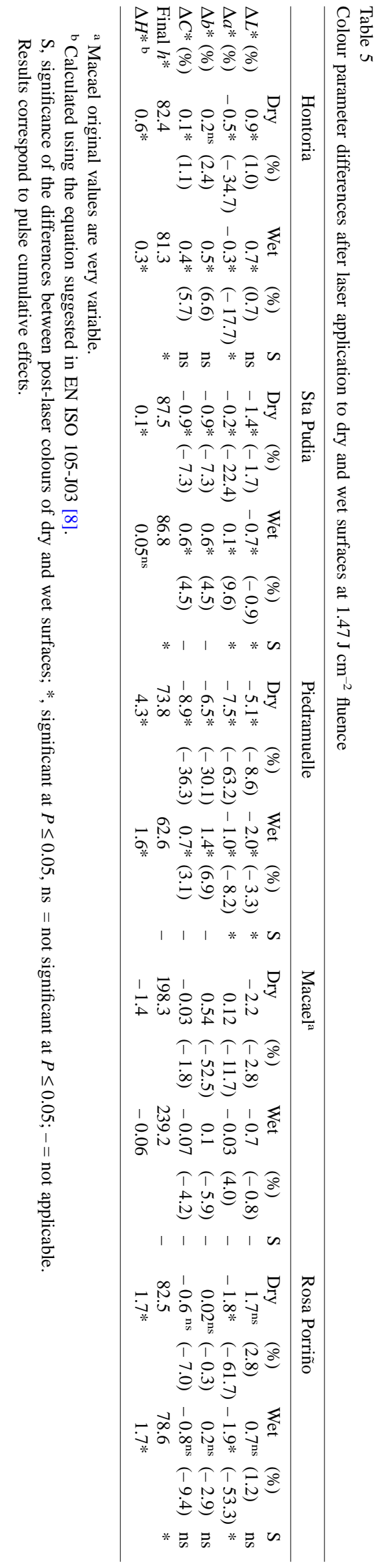

crease. The response of both dry and wet Rosa Porriño granite surfaces is quite similar, although the change is slightly lesser on wet surfaces.

To establish possible causes for colour changes, opaque minerals of stones were examined under reflected-light optical microscopy. Almost no opaque minerals were observed in Hontoria limestone both prior to and after laser application. Santa Pudia contains mainly goethite-limonite and occasional haematite and magnetite. No substantial change is observed after laser irradiation, goethite-limonite remaining apparently intact. Piedramuelle comprises haematite as well as limonite-goethite. After laser irradiation, the stone's orange background is gone and no haematite is observed. Macael does not exhibit major change and contains some pyrite minerals prior to and after laser application. Rosa Porriño shows very occasional molybdenite and rutile and no changes are observed in opaque minerals after irradiation.

The behaviour of the selected stones under laser irradiation could be summarised as follows:

The response of the three limestones to laser radiation depends on the Fe-bearing minerals (mainly oxides or hydroxides) dispersed in the stone. This is evident in Santa Pudia and Piedramuelle. The dramatic change of Piedramuelle could be mainly attributed to the haematite response to laser radiation.

The response of Macael marble varies strongly depending on the presence of bands rich in muscovite and pyrite, the state of the surface, and the preferential crystal orientation of the irradiated section [9]. This stone shows no Fe-oxides. Colour changes could be partly associated to a photo-oxidation of Fe (pyrite) [3]. Darkening might be also due to calcite spalling depending on crystal orientation [9].

The main colour changes in Rosa Porriño granite are associated to changes in the $\mathrm{Fe}_{2} \mathrm{O}_{3}$ comprised in potassium feldspars. However, Rosa Porriño is a polychromatic stone composed of several differently coloured minerals: $63 \%$ "light" coloured $\left(L^{*}>60\right)$ minerals, such as potassium and plagioclase feldspars, and 37\% "dark" $\left(L^{*} \leq 60\right)$ minerals, including quartz and biotite. The total colour change $\left(\Delta E^{*}\right)$ of dry surfaces at a $1.47 \mathrm{~J} \mathrm{~cm}^{-2}$ fluence is around 2.5 . As light minerals show an average $\Delta E^{*}$ around 3 and dark minerals around 1.1 (probably associated to biotite), the total colour change could be calculated as follows:

$$
\Delta E_{\mathrm{RP}}^{*} \approx 0.65 \cdot \Delta E_{\text {light minerals }}^{*} \times 0.35 \cdot \Delta E_{\text {dark minerals. }}^{*}
$$

Finally, colour measurements made possible to establish stone damage threshold to laser irradiation. The initially established damage thresholds for dry surfaces are: Hontoria $=1 \mathrm{~J} \mathrm{~cm}^{-2}$, Santa Pudia $=0.75 \mathrm{~J} \mathrm{~cm}^{-2}$, Piedramuelle $=$ $0.25 \mathrm{~J} \mathrm{~cm}^{-2}$, Macael $=0.37 \mathrm{~J} \mathrm{~cm}^{-2}$ and Rosa Porriño $=$ $0.5 \mathrm{~J} \mathrm{~cm}^{-2}$. However, colour change is considerably less dramatic when the stone surface is moistened. All the selected stones after laser application shift to yellowish hues, showing hue $(h)$ values closer to 90 (pure yellow). 


\section{Conclusions}

Q-switched Nd:YAG laser irradiation can induce colour changes on the stones depending on their mineralogical composition and the irradiation fluence. In this research, a "colour-change" threshold fluence has been used to establish the application limits of this laser-cleaning technique for different types of building stone.

The presence of some elements or compounds, mainly Fe-rich minerals, dramatically conditions stone response to $1064 \mathrm{~nm}$ laser irradiation. In this case, the $a^{*}$ parameter or the red component is the most affected. This is very evident in stones containing haematite $\left(\mathrm{Fe}_{2} \mathrm{O}_{3}\right)$. In this way, whitish limestones could be cleaned by laser irradiation without perceptible colour changes whereas reddish stones would suffer strong colour variations.

Finally, colour changes are less dramatic when the stone surface is moistened. Consequently, a thin water layer on stone surfaces can help to diminish the colour changes induced by laser irradiation.

\section{Acknowledgements}

The authors wish to acknowledge the financial support of this research to CICYT-Spain (Project 1FD97-0331-C03$01)$.

\section{References}

[1] J.F. Asmus, The development of a laser statue cleaner, Proceedings of the 2nd International Symposium on the Deterioration of Building Stones, Athens, Beloyannis Ing. Chim, 1976, pp. 137-141.

[2] M. Cooper, Laser Cleaning in Conservation, An Introduction, Butterworth-Heinemann, Oxford, 1998.

[3] S. Siano, F. Fabiani, R. Pini, R. Salimbeni, M. Giamello, G. Sabatini, Determination of damage threshold to prevent side effects in laser cleaning of Pliocene sandstone of Siena, J. Cult. Heritage 1 (2000) S47-S53.

[4] M. Labouré, P. Bromblet, G. Orial, G. Wiedemann, C. SimonBoisson, Assessment of laser cleaning rate on limestones and sandstones, J. Cult. Heritage 1 (2000) S21-S27.

[5] D. Eichert, V. Vergès-Belmin, O. Kahn, Electronic paramagnetic resonance as a tool for studying the blackening of Carrara marble due to irradiation by Q-switched YAG laser, J. Cult. Heritage 1 (2000) S37-S45.

[6] A. Aldrovandi, C. Lalli, G. Lanterna, M. Matteini, Laser cleaning: a study on greyish alteration induced on non-patinated marbles, J. Cult. Heritage 1 (2000) S55-S60.

[7] EN ISO 105-A05, Textiles - Tests for Colour Fastness. Part A05. Instrumental Assessment of Change of Colour for Determination of Grey Scale Rating, 1997.

[8] EN ISO 105-J03. Textiles - Tests for Colour Fastness. Part J03. Calculation of Colour Differences.

[9] C. Rodríguez-Navarro, K. Elert, E. Sebastián, R.M. Esbert, C.M. Grossi, A. Rojo, M. Montoto, J. Ordaz, F.J. Alonso, C. Escudero, M.C. Pérez de Andrés, Q-switched Nd-YAG laser cleaning of white marble: induced damage evaluation through combined use of XRD and SEM, Lasers in the Conservation of Artworks, LACONA 4, 2001, pp. 49-52. 